\title{
Boston: MRS Fall Meeting in Review
}

\section{More technical reports, broader participation, highly successful equipment exhibit}

More than 1,950 materials scientists/researchers representing the United States, France, England, Japan, Germany, Scandinavia, China, Israel, India, and other geographic regions spent the week in Boston in November marking the 1984 MRS Fall Meeting and making it the most successful MRS meeting to date, both in size and scope. The Society was particularly pleased to note that attendees included $\mathrm{H}$. William Koch, executive director of the American Institute of Physics; H. Kamimura, president of the Japanese Physical Society; Mildred Dresselhaus, president of the American Physical Society; and Arthur von Hippel, namesake of MRS' most prestigious award.

Over 900 papers ( 100 more than presented at the 1983 Meeting) representing the work of more than 2,000 researchers were presented in 17 symposia, including tutorial reviews for the nonspecialist (Symposium X) and poster sessions. The unusually mild November weather, originally thought to be a blessing for out-of-town visitors, turned into a thick blanket of fog on Wednesday, grounding planes and stranding a number of latearriving speakers at distant airports. But true to their innovative nature (and strong desire not to miss the Meeting), many of the delayed speakers arranged alternative means of transportation and reached the Marriott in Boston just in time to be whisked into their session rooms to make their presentations.

This example of dedication and perseverance on the part of the attendees was also seen on a daily basis in the meeting rooms, where speakers were drilled for additional data, and discussions threatened to overrun time limitations. Many of the more relentless question-and-answer periodsto the obvious delight of the speakers-spilled out into the corridors between sessions and during breaks. And despite the occasional relocation of some sessions to larger meeting rooms, in order to accommodate unanticipated high levels of attendance, the symposia ran smoothly.

\section{MRS Firsts}

Two new features of the Fall Meeting were introduced this year, through the help of the American Institute of Physics. The first MRS Exhibit included 84 equipment displays including temperature measurement and control systems, Auger/ESCA/SAM/SEM/SIMS systems, chemical additives, superconducting magnets, cryogenic pumps, color graphic terminals, gas purification systems, MBE instrumentation, lasers, fittings, valves, cameras, and semiconductor materials, to name a few. The lattice of booths in the exhibit hall bustled from opening day Tuesday through the Thursday afternoon closing. Exhibitors and attendees alike expressed their pleasure with these face-to-face meetings and demonstrations. "Better than most shows" was a frequently heard comment in the aisles.

Another AIP-run activity new to the Fall Meeting was the Job Placement Center. The threeday center featured 42 companies and entertained interest from over 100 professionals attending the

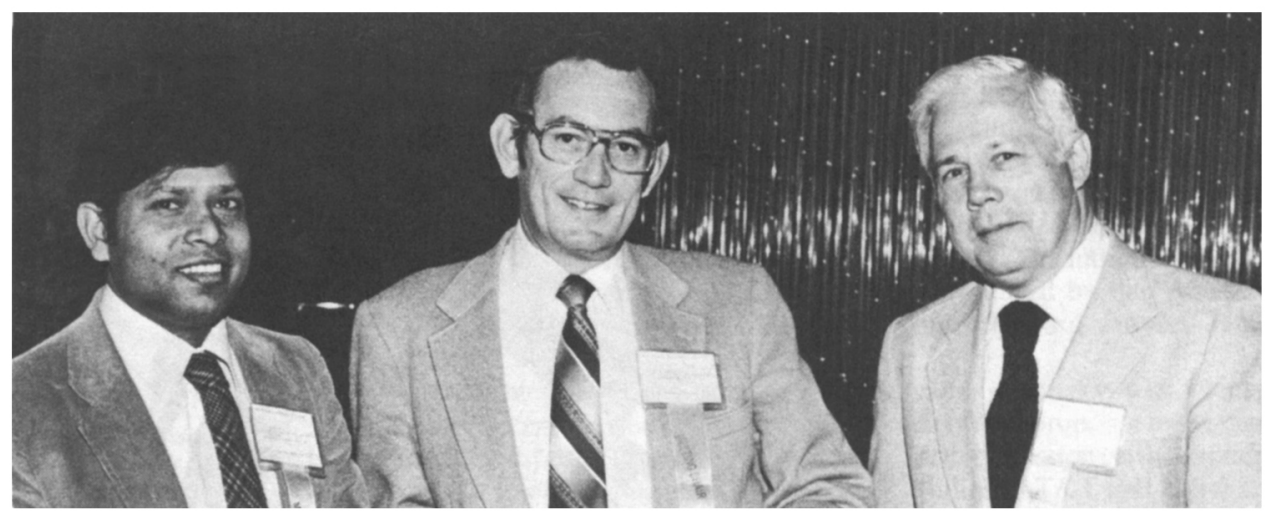

Fall Meeting Program Chairpersons (left to right) Jagdish Narayan, Paul Peercy, and Walter Brown.

Meeting. An AIP spokesperson called the center "very successful for a first-time professional service," noting that a strong representation of recent graduates as well as seasoned professionals sought out the services offered by the center.

\section{Lecture/Award Highlights}

A large audience gathered for Monday evening's Plenary Lecture to hear Dean Eastman, director of the IBM Watson Research Center's Advanced Packaging Technology Laboratory, speak on "Major Facilities for Materials Research." Dr. Eastman's address was a long-a waited sequel to the 1983 Plenary Lecture in which Dr. George Keyworth, Presidential Science Advisor and Director of the Office of Science and Technology Policy, addressed the need for evaluating major materials research facilities in this country. As co-chairman of the committee formed to study these needs, Dr. Eastman discussed the criteria used by the committee and the conclusions it drew concerning equipment needs and research priorities. (See Dr. Eastman's lecture in this issue.)

And what do bi-colored python rock snakes have to do with materials research? They are an indispensible part of it, according to Von Hippel Award recipient Walter L. Brown of Bell Laboratories. Dr. Brown touted the qualities essential for scientists to be effective, while entertaining a ballroom full of Fall Meeting attendees at the Wednesday evening award ceremony. (See more on the ceremony and comments about him from his admiring colleagues in this issue.)

\section{Short Courses}

As the technical symposia drew to conclusion on Friday, eight short courses got underway under the tutelage of Thomas Seidel, Leonard C. Feldman, Herbert M. Cox, and David B. Fraser of Bell Laboratories; James K. Hirvonen of Zymet; James W. Mayer and Gary Wicks of Cornell University; Mars H. Hablanian of Varian Vacuum Division Linn W. Hobbs of MIT; Fred Pettit of the University of Pittsburgh; Jesse Lumsden of Rockwell Science Center; and Don Mitchell of the National Research Council of Canada.

The eight courses focusing on materials research techniques were attended by a total of 156 students, whom the instructors characterized as top notch and credited with the high-quality, probing interaction evident in the classrooms. The attendees, as well, indicated their satisfaction with the level and depth of material covered.

The level of success anticipated for this short course series was surpassed, according to David Zehner, 1984 co-chairman of the Education Committee responsible for short course activities. He reflected on the fact that the last series of courses, held in conjunction with the 1983 MRS Fall Meeting, consisted of three courses with a total enrollment of 41 students.

"The Fall Meeting courses," he stated, "are an indication of the desire for solid, timely continuing education programs by members of the Society . and the success of the short course program is a result of the enthusiastic members who have worked hard to make it high caliber."

The Whole-Only as Good as Its Parts

Zehner's comments can be extrapolated to the Fall Meeting as a whole. The efforts of Program Chairpersons Walter Brown, Jagdish Narayan, and Paul Peercy, and the 43 symposia chairpersons, as well as the vigor with which the attendees participated throughout the week, generated a landmark MRS meeting. The technical program contained a rich blend of technical information from the many disciplines inherent in materials research. And, as was obvious from the discussions among attendees in and outside of the sessions, new ideas were spawned which will develop into new challenges and applications that will undoubtedly be reported and scrutinized during future MRS meetings.

In recognizing the work of the symposia chairpersons which resulted in the overwhelming success of the Meeting, MRS President Woody White summed it up best by saying, "The effort of the symposia chairpersons is deeply appreciated by the MRS. The quality of the technical program that they organized contributed greatly to the future growth and prosperity of the Society. But perhaps more important, their work provides a single barometer that researchers worldwide can use to gauge the state of the art in 1984. This is the real success of the Fall Meeting." 